\title{
FACILITATING EFFECTIVE STUDENT LEARNING ON SUBJECT MATTER "SIMPLE COLLOIDS" THROUGH DEMONSTRATIVE EDUCATIONAL VIDEOS
}

\author{
Anna Thysiadou ${ }^{1}$ iD, Vaso Gaki ${ }^{2}$ iD \\ ${ }^{1}$ Department of Chemistry, International Hellenic University (Greece) \\ ${ }^{2}$ Department of Chemistry, Aristotle University of Thessaloniki (Greece) \\ thysiadon@hotmail.com,gakivicky@gmail.com
}

Received April 2020

Accepted August 2020

\section{Abstract}

Abstract: The introduction of the computer into the educational process is a fact. The educational use of new technologies creates a new, more appealing and enjoyable learning environment. The introduction of new technologies into school differentiates the role of the professor by giving him/her a guiding character in a process of experiential approach to knowledge. In the present paper a proposal for the teaching of the chemistry module "Simple Colloids" is presented, with the contribution of video recorded educational experiments. Complete experiments on the subject of "Simple Colloids" and their properties are presented, aiming at familiarizing students with this theory.

Keywords - Simple colloids, Chemistry, Experiments, Digital educational video, Didactic.

\section{To cite this article:}

Thysiadou, A., \& Gaki, V. (2021). Facilitating effective student learning on subject matter "simple colloids" through demonstrative educational videos. Journal of Technology and Science Education, 11(1), 4-15. https://doi.org/10.3926/jotse.1001

\section{Introduction}

The introduction, the good use and application of Information and Communications Technology (ICT) in the educational process is followed by underlying learning theories, models and techniques of successful integration. There are theories that are linked with behaviourism, which consider learning as a process of acquiring knowledge, those who regard learning as a process of knowledge creation and are associated with constructivism, as well as those theories that regard learning as a result of participation in social groups and are related to socio-cultural theories (Koulaidis, 2007; Education \& Training Division, 2013).

According to Behaviourism, the application of appropriate teaching methods is sought in order to act as stimuli, which can lead to the desired learning outcomes. Learning is defined as a modification in the student's behaviour that arises as a result of the teaching of the professor and in parallel with the contribution of exercises given to the student by the professor. Learning is achieved by enhancing the student's desired behaviour. In keeping with Behaviourism, learning occurs by following two courses-ways, through positive reinforcement equivalent to reward or through negative reinforcement, such as a 
reprimanding or a negative comment and evaluation (Koulaidis, 2007; Education \& Training Division, 2013).

Following the bibliographical references of Messrs. Frére and Matsagouras (Freire, 1977; Matsagouras, 2011), the model of teaching that is compatible with this theory has been called a model of transfer of knowledge and alternatively a narrative, teacher-oriented, namely professor-oriented, but also a frontal model of teaching. During the course, the presence and the actions of the professor are predominant and there is little room for active participation of the student. The student, listens to the professor and follows his/her instructions, answers questions with which the professor tries to elicit the right answers, and evaluates and rewards the successful assimilation of the subject matter, not their reflection, collaboration and development of critical thinking (Koulaidis, 2007; Cosgrove, 2005).

Constructivism is based on the principle that people are actively building knowledge through the attribution of meaning in their cognitive experiences and not a passive host of information and knowledge (Kelly, 1955). Learning is seen as a cognitive process during which the individual builds meanings as a result of the organization and adaptation of new information to existing cognitive structures and knowledge. Consequently, the student learns when engulfed in an environment rich in cognitive stimuli, which enables him/her to actively interact with this environment (Koulaidis, 2007; Education \& Training Division, 2013).

Sociocultural theories on learning are mainly based on Lev Vygotsky's socio-cultural theory and address learning as a process of social interaction between the individual and the social environment in which this person lives and interacts. The individual does not construct knowledge individually in the frame of a cultural and communicative "gap". On the contrary, learning takes place in specific social and cultural contexts (language, stereotypes, perceptions) and is created by the interaction of the individual with other people, in specific communication circumstances and through the implementation of common activities (Koulaidis, 2007; Education \& Training Division, 2013). In the sociocultural theories of learning, the role of communication, the use of language, the comprehension and, in general, social interaction with other people is extremely important (Vygotsky, 2008). Therefore, it is becoming clear that socio-cultural theories support collaborative learning in all its forms and thus for an organized lesson to take these theories into account it must be carefully designed so as to encourage collaboration and social interaction among students (Koulaidis, 2007; Education \& Training Division, 2013).

The motive for the designing and implementation of video recorded educational experiments was the identification of the teaching problems occurring during the teaching of the subject "Simple Colloids".

The aim of the study is to access the misconceptions of students concerning the curriculum of a subject matter and its structure are due to the difficulty of clarifying many complex concepts. The main source of the problem is the fact that appropriate methods for teaching the lesson have not been provided. For the more effective teaching of this module, it was necessary to combine teaching with the actual interaction with the phenomenon. Typically, the concepts are separated and there is no link between them while the technology exploitation is absent. Through the students' answers, it was observed that there are several misconceptions about solutions, mixtures, suspensions, and a wider difficulty in separating them. This derives from the fact that students are deeply influenced by everyday experiences that usually contradict the real scientific explanation.

\section{Methodology}

Bezemer and Kress (2008) find that the learning materials used in education are increasingly based on the image while reducing the extent of the text (Kress, 2003). Camcorders initially as well as other devices that allow recording videos such as mobile phones are now economically affordable to the general public. The video can be edited on any computer using software that is either affordable or free of charge. Nowadays, the video is a key component of the communication process owing to the fact that it now dominates as a communication exchange product. 
Given the pedagogical design, video recorded educational experiments were created for the module of "Simple Colloids". Then the unedited material was processed for its fit into the final video. This material was processed with image editing GIMP, audio editing Audacity and video editing software Blender. The final video was created using Blender Video Sequence Editor. The creation of the video encountered a variety of difficulties, both design and technical.

Designing a digital text such as a video is very different in comparison, for example, a written text, as it requires another approach and different skills. In particular, the presentation of information with the help of a video recording is a new area where familiarity is required. The most important parameter was the image and sound combination in the context of the presentation of the information. The final video recorded educational experiment consisted of narration (story script) and images. The proper combination of all these elements, so as to capture the content of the script without gaps and ambiguities in the course of the process, was a major challenge. Therefore various tests were required before the final version.

The implementation of the video tutorial required familiarity with the software tools there were used. In particular, the basic requirements related to familiarity with the software, recording, processing and mixing audio, as well as video editing. The composition of video elements such as narration with sound and video has been an important technical challenge. Difficulties have emerged from combining narrative parts with the corresponding images and video clips.

As is known, there are three states of matter, solid, liquid, gas, freezing and condensation. Transitions from one situation to another are known as melting, evaporation and sublimation, respectively. This applies to both pure ingredients and homogeneous mixtures in which chemicals are found on a dispersed scale. The intermediate class of materials between pure components and molecularly dispersed systems where, although one component is micro-dispersed in another, the degree of dispersion or particle size is very different from those of the molecular systems. These systems are called colloidal systems and have very special properties. The continuous and discontinuous phase can be either solid or liquid or gas.

Colloidal systems are of great importance for the life of humans, animals and plants owing to the fact that they are their main components and on the other hand that they are found in a large number of industries (Cosgrove, 2005). According to the theory of physical state colloids can be classified in categories which are foam, solid foam, aerosol, emulsion, gel, solid aerosol, sols and solid sols. Milk belongs to emulsions. Emulsions are this category of colloids in which both dispersed phase and dispersion medium are liquids. In reality milk is a stabilized oil-in-water emulsion in which fat globules is dispersed in water (Bouchoux, Qu, Bacchin \& Gésan-Guiziou, 2014).

The educational tool developed in this paper is considered to be a proposal for the introduction of module "Simple Colloids", to which little reference is made in the teaching of chemistry so as to be able to act as a first contact with the basic concepts of "Simple Colloids". Following, it will help in combination with the tools provided to gain a deeper understanding of "Simple Colloids" and finally will offer a small piece of help in clarifying the wider concept of the subject.

After the videos are projected, a student-friendly environment is offered, for experimentation, exploratory learning, constructivist learning activities, and the cultivation of their desired analytical and synthetical thinking. The combination of video recorded educational experiments and chemistry teaching can be a fertile field for research and experimentation. Trainees experience the freedom to experiment, to socialize and ultimately to gain knowledge through this experience. With these learning strategies, students can be activated and stimulated cognitively in order to achieve the desired learning outcomes, such as facilitating understanding of key concepts and increasing their engagement through praxis-based activities.

\section{Results and Discussion}

Usually, the problems given to students are not related to their everyday life and their interests, with the consequence that they do not mobilize them sufficiently to deal with their solution. In an attempt to overcome similar issues, there is a promising teaching proposal, which is no other than video recorded 
educational experiments, something that can be an effective teaching approach for the professor who knows how to use it. Taking into account the specific needs and the interests of the students according to their cognitive background, new didactic approaches were sought in order to achieve the best learning outcomes (Thysiadou, Mitropoulos, Sakla \& Giannakoudakis 2019; Thysiadou, Solomanidou \& Christoforidis, 2020).

The effectiveness of the experiment for the promotion of the assimilation of the concepts in teaching and learning chemistry is undoubted, although some of the experiments indicated in school textbooks may, for many and varied reasons, be the cause of an accident for the professor and students in the School Physical Sciences Laboratory.

The experiment with the use of the computer is a way to overcome several difficulties as it does not require the existence of a laboratory. It also makes something visible because as it evolves quickly, it would not be perceived if it was done in the conventional laboratory through the naked eye without the necessary explanations at the right time. A time-consuming experiment takes place now in a very short time and in the classroom. Another key advantage is the flexibility in repeating an experiment many times. Many are the times, for random reasons, in which the experiment is not repeated. In addition, here, the experiment always succeeds. It has happened many times, that an experiment, which has been prepared already the previous day, was not successful during the lesson. Moreover, something very important is that with experiments of this sort, the professor's stress is limited, that which is related to whether the time will be sufficient to show what he/she wants, because the experiment can be timed and therefore the needed time can be attributed to it. Last but not least, in many cases the use of video for the explanation of the theory is the only solution for the e-learning procedures (e.g. during the COVID 2019 there is not possibility for real experiments in the schools/universities).

That is the reason why it may be advisable to have the presentation of the experiment video recorded by the professor. In the present paper, we are proposing and presenting interactive multimedia demonstration experiments with text, images, video and sound. Step by step, the procedures are presented for performing the experiment. The corresponding educational material such as application form and evaluation testing form is also given.

This simple form of presentation is advisable. Because, on one hand, there is no need for specific knowledge of the use of multimedia software by anyone who would like to repeat it and on the other hand the necessary technical equipment, for example, a digital video camera or a digital camera capable of capturing video for 30 seconds or more, is not scarce, even though it is considered a rather non-existent equipment in our public schools.

Furthermore, this material, or something similar, can both be easily copied, as it can be found on a website where educational material is available in order to be used by various students to study at home - and be disseminated to anyone else interested. Video tutorials are described in detail in the following subunits.

\subsection{The Currents of Colour}

The purpose of this experiment is to prove that a detergent can cause the movement of the other molecules. The materials to be used are milk, food colours (red, yellow, and blue) as well as liquid detergent. In reality milk do not belong to the category of the common liquids such as water because is a colloidal suspension where small blobs of fat and proteins are uniformly distributed in a watery liquid which is known as whey. Both particles fat and proteins will not naturally agglomerate however float in solution. In the experimental process, initially, enough milk is placed on a dish to cover its base. Afterwards, two drops of each food colour are added with a distance between them. The food colouring specially "paints" the fat, however the colour pigments are more resoluble in the fat rather than water. This occurs owing to the nature of the molecular interactions. This characteristic has as result that the food colouring creates an enormous amount of colour balls, which are suspended into the liquid phase of the milk. From the detergent bottle, which must be placed above the centre of the dish, only one drop is used. Finally, the movement of colours is being noticed. 
As the experiment progresses as far as it concerns the colour, a rapid movement out of the direction of the centre of the dish is observed. Rotating movements of the individual colours appear along the surface of the milk during the first two minutes (Figure 1). Within these 1-2 minutes, the moving colours begin to blend together having as a result the formation of a grey mixture.

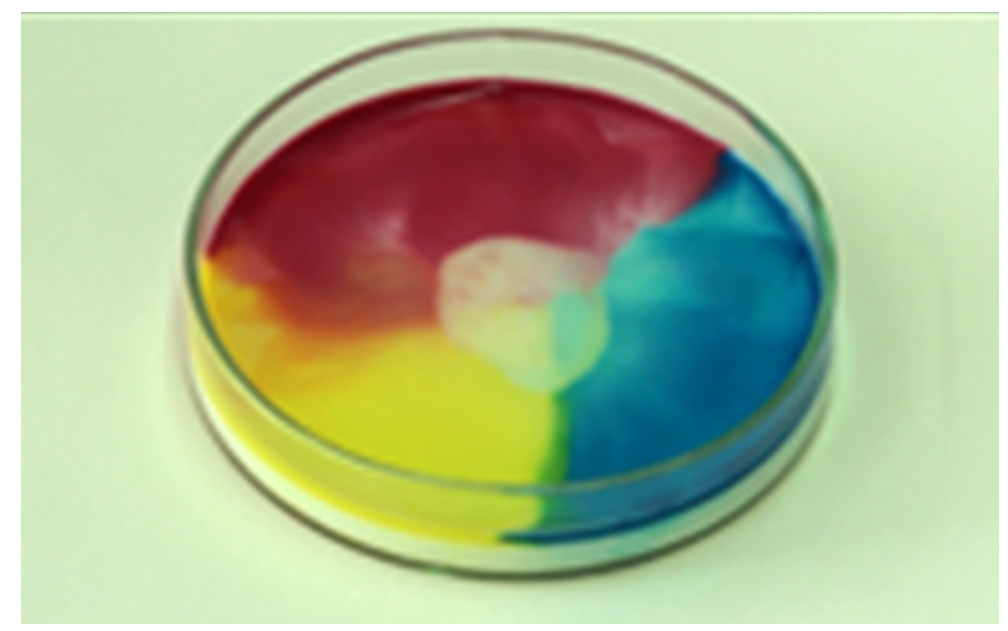

Figure 1. Rotating movements of the individual colours

The drops of colour temporarily remain separated. The lipid droplets of milk do not mix well with the aqueous food colour and therefore the colours are kept separate. The colours move outwards because the water surface molecules are pushed by the molecules of colour with the same force in all directions. By dropping detergent in the centre the attraction by the water molecules weakens and the strongest water molecules adhere. The coloured molecules are drawn by them along the water surface towards the edge of the dish. As the drops of lipids break into smaller portions because of this detergent, they spread out allowing the pigment and milk to mix (Figure 2). The addition of the detergent has as results the movement of the liquid. The reason for this is the fact that the molecules of the detergent comprised of two parts i) the "hydrophilic" head and ii) the "hydrophobic" tail, hence the soap molecules "skate" on the surface of the milk.

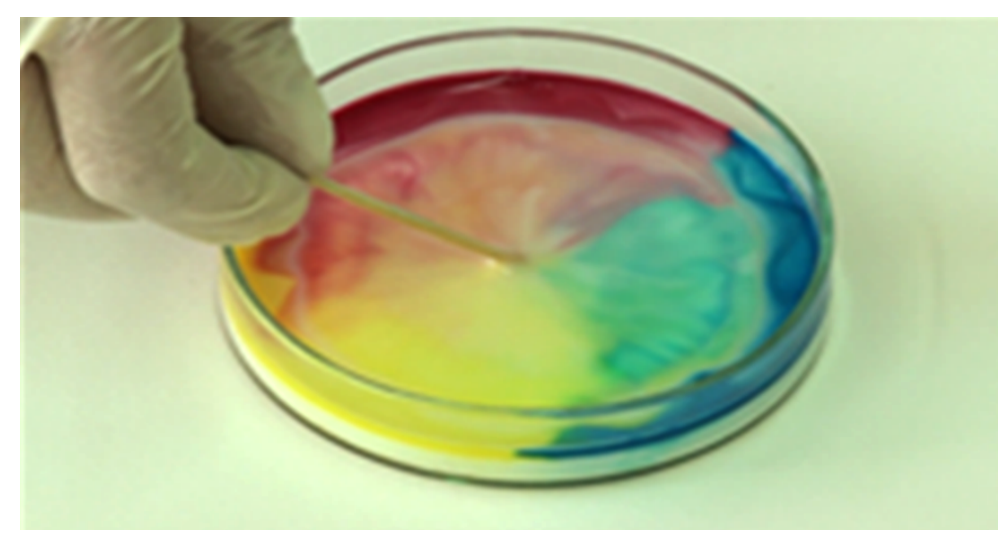

Figure 2. By dropping detergent in the centre the attraction by the water molecules weakens

\subsection{Coagulated Milk and Whey}

The purpose of the experiment is the separation of the two parts of the milk, the solid from the liquid. The materials to be used to carry out this specific experiment are milk and vinegar $(15 \mathrm{ml})$. In the experimental process, first, fill the conical flask with fresh milk. Afterwards, add 2 tablespoons $(30 \mathrm{ml})$ of vinegar and shake very well. Allow the conical flask to rest for two to three minutes. 
The milk is separated into two parts, consisting of a white solid and a clear liquid (Figure 3). This result occurs because the simple colloid is a mixture of liquid and very finely diffused particles which spread throughout the liquid. Milk is an example of a simple colloid. The solids in the milk are dispersed smoothly through the liquid. The vinegar joins small insoluble particles together, forming a solid part called coagulated milk. The liquid part is rendered as whey.

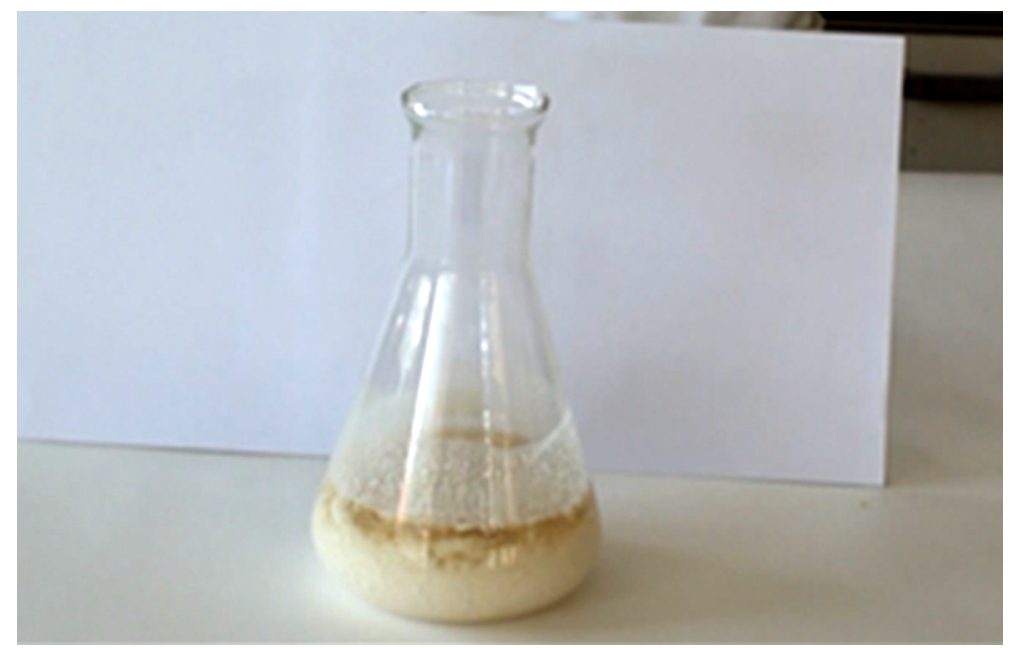

Figure 3. The milk is separated into two parts

\subsection{Explosion of Colours}

The purpose of this experiment is to produce explosive coloured bubbles. The materials to be used are liquid cooking oil, food colouring (red, yellow, green), a $500 \mathrm{ml}$ glass beaker, a $25 \mathrm{ml}$ glass beaker and a stirrer; an amount of water is initially placed in the beaker $500 \mathrm{ml}$. Thereafter a spoonful of oil is put in the small beaker $(25 \mathrm{ml})$, add 4 drops of each colour pigment are added and use the stirrer is used to blend the oil and the colours until they are thoroughly mixed. The mixture of oil and food colours is placed in the water in the large beaker. Observe the surface as well as the side of the beaker for 5-10 minutes. Oil which incorporated in the water is an emulsions and form a colloidal system which have oil droplets dispersed through the water. Water is the continuous phase of the presented colloid while the oil consist the dispersed phase. The molecules of oil remains separate from the molecules of the water owing to the fact that the oil characterized from lacks polarity and float on the surface because oil is lighter (has less density) than water. From the chemical point of view this phenomenon occurs because oil has composed of carbon and hydrogen atoms which make up non polar chemical bonds. On the other hand water is a molecule from oxygen and hydrogen atoms which make up polar chemical bonds.

The small surface of oil stains that got dirty with spheres of food colours rises to the surface of the water (Figure 4). Separate colour spheres appear and explode outward, producing flat colour circles on the water surface with colour waves sinking down into the water (Figure 5). The food colouring has a little higher relative density compare to water hence are heavier than oil so has the trend to dip in the water. Through the oil the food colouring separated in small droplets however a small amount of oil remain on these droplets and has as a result to retard the absorption of the colour, generating extended colour paths which seem like fireworks. 


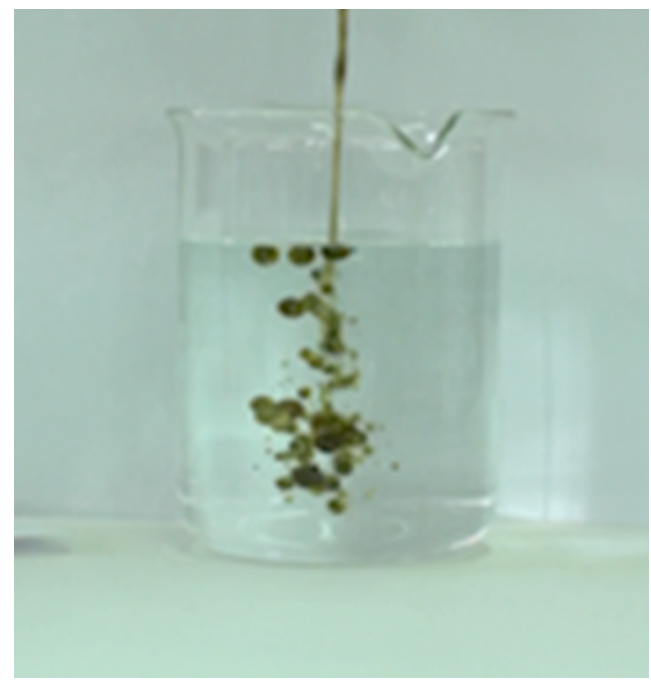

Figure 4. The small surface of oil stains rises to the surface of the water

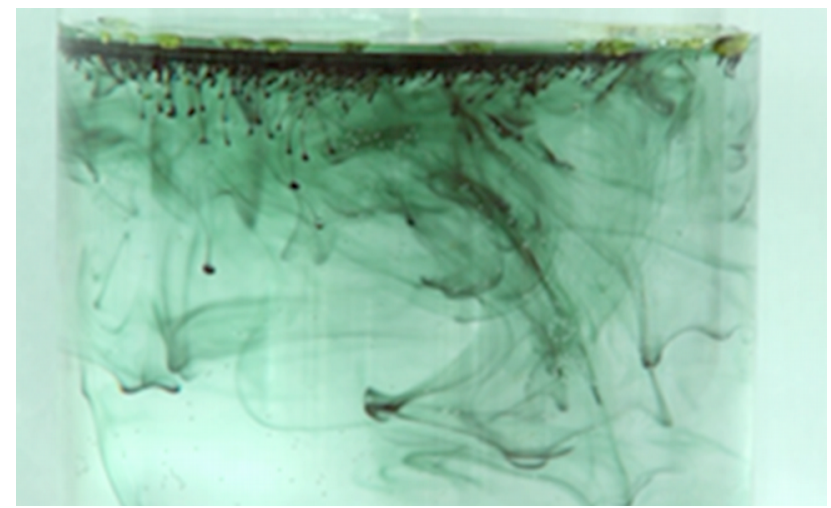

Figure 5. Colour spheres appear and explode outward

Because of the fact that food colours are water soluble, they remain like small spheres all over the oil on the water surface. Round coloured spheres sink and pierce the oil layer and dissolve in the water layer below (Figure 6). At the moment when small drops of colour touch the water, they quickly disperse on the surface and long colour currents begin to descend (Figure 7).

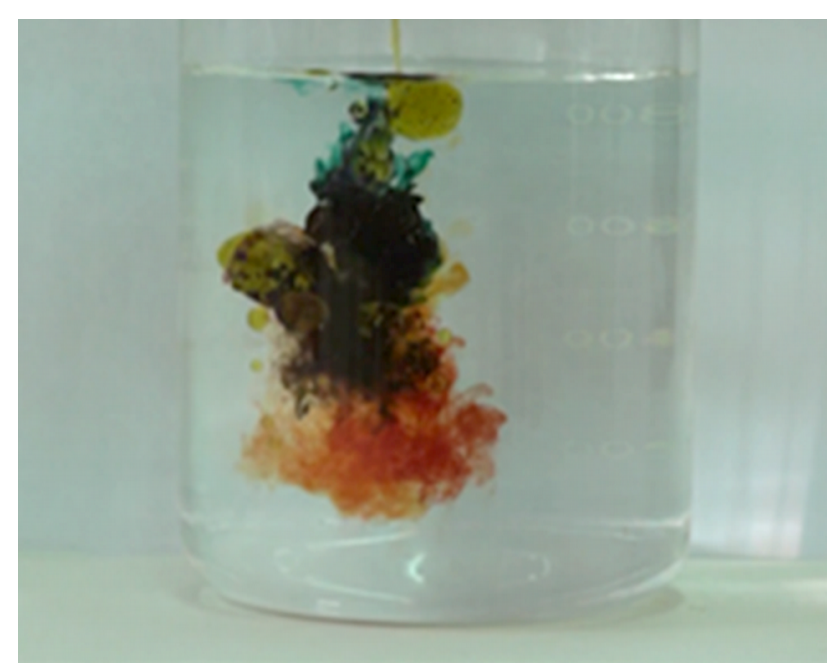

Figure 6. Round coloured spheres sink and pierce the oil layer 


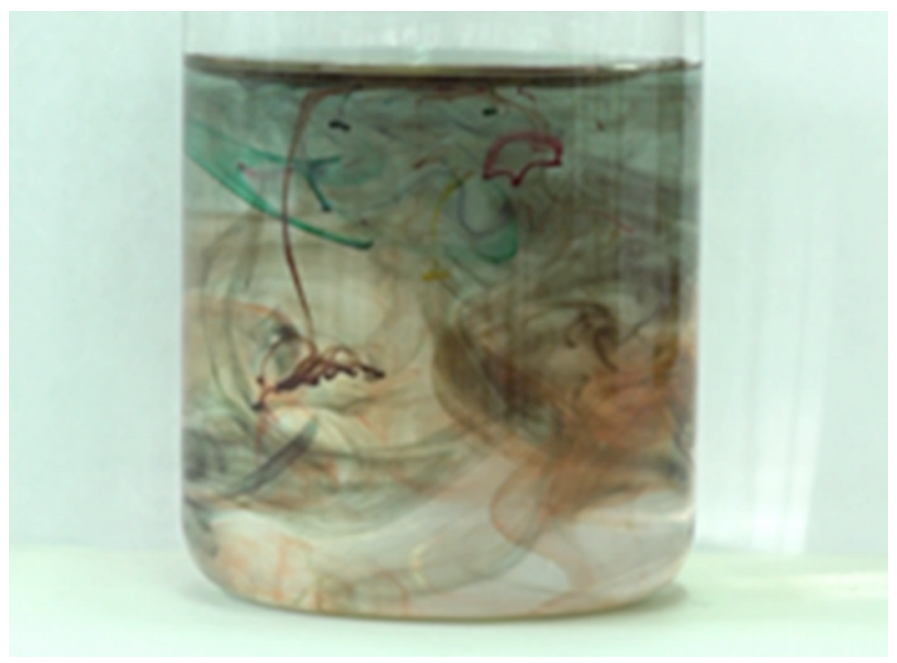

Figure 7. Small drops of colour touch the water

\subsection{Preparation of Simple Colloid from Eggs}

The purpose of this experiment is to prepare "Simple Colloids" from simple materials such as eggs. The materials to be used are eggs (without yolks) and mechanical stirring (hand mixer). In the experimental process, the egg whites are initially mixed with the mixer (Figure 8).

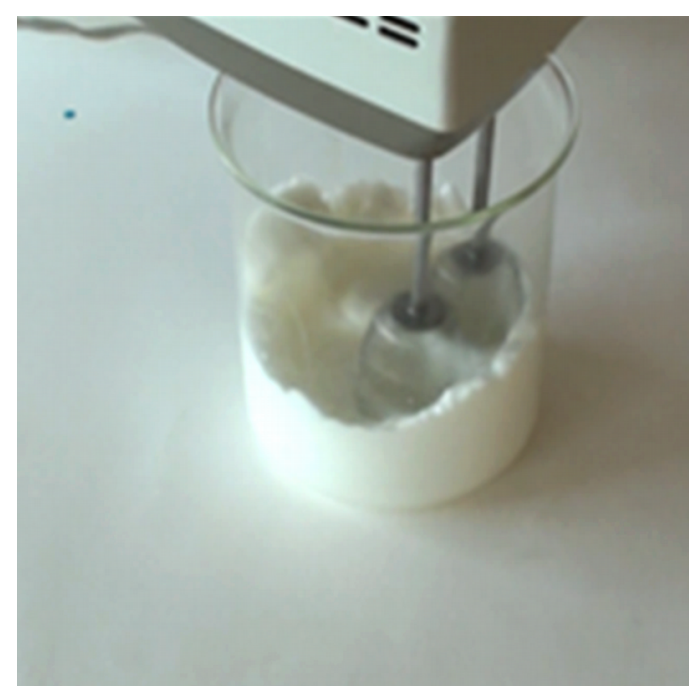

Figure 8. Mixed the egg whites with the hand mixer

After stirring them for five minutes, it is noticed that the mixture has thickened and that it does not fall when you turn the spoon is turned over. White of egg composed of $90 \%$ water while the related molecules are proteins which formed from amino acids. Some amino acids are hydrophilic while others are hydrophobic. As liquid white of egg is stirred, air bubbles are formed which are characterised as a colloidal dispersion. Colloidal dispersions denote a category of emulsion in which a gas (air in this experiment) is dispersed through a liquid (white of egg here) creating a uniform blend. Owing to the stir albumen proteins unfold and then these protein network hold the air bubbles. This procedure forms the meringue which is a solid foam with gas as dispersed phase and solid as dispersant phase (Figure 9).

Educational material (application form and evaluation questions) was created for both the professor and the student, related to the subject matter of the teaching module of the Chemistry course. More specifically, the titles of the educational material for the application form are: Determination of colloidal systems with the help of the Tyndall effect, Separation of "Simple Colloids", solutions, mixtures by filtration, Preparation of "Simple Colloids", Production of foam for extinguishing fire. The evaluation questions that were created were related to the respective subunits of the lesson which the students were 
taught by both the theoretical and experimental (video) part of this subunit. The application form that was created contained questions of both open and closed type (for example true/false) and had to be answered at the predetermined time according to the professor's instructions. Students could work at both an individual and a team level. Forms were created for the professor. These forms concerned material such as end-of-lesson goals, the time of application, the method for organizing the class, and finally the steps of the development of the educational process.

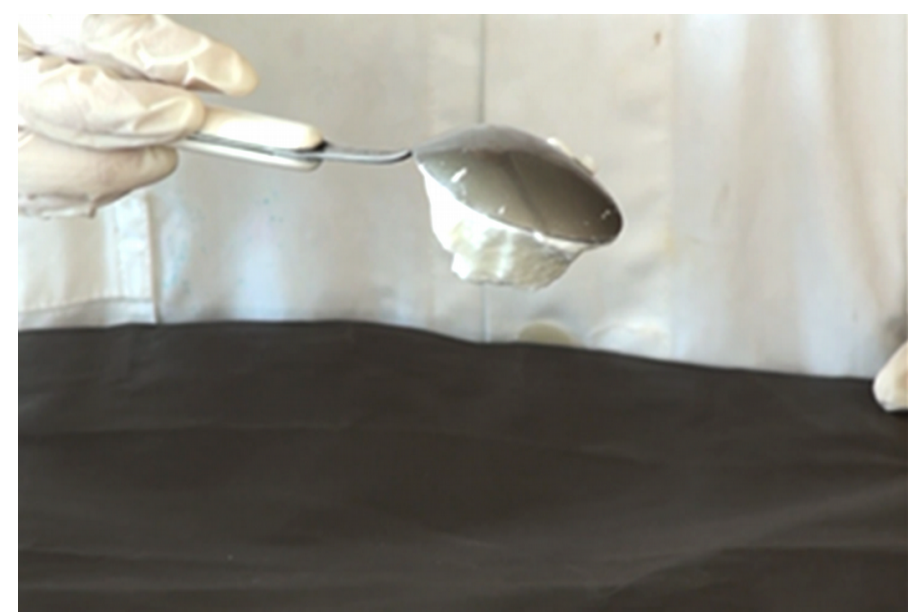

Figure 9. Preparation of meringue

First of all, participants completed a demographic questionnaire followed by a pretest to determine their prior domain knowledge. At the end of the first semester, a questionnaire was given to 120 students of the School of Science, in the International Hellenic University. The participants were 60 women and 60 men.

Table 1 shows the results of the questionnaire (8 questions) according to the question (If the educational video helped students to comprehend the chemistry theory). Using factor analysis, emerge only 3 factors without irrelevant factors. The first factor refers to the motivation that increases the use of the educational video. The second factor is the increment of the efficiency ("doing the thing right") of the course using the material available on the educational video and finally the third factor is augment of the effectiveness ("doing the right thing") which achieved by using educational video to support the lessons.

\begin{tabular}{|c|c|c|c|}
\hline & \multicolumn{3}{|c|}{ Component } \\
\hline & 1 & 2 & 3 \\
\hline $\begin{array}{l}\text { Courses given with educational video increase the interest } \\
\text { in the lecture. }\end{array}$ & .865 & .050 & -.009 \\
\hline Using educational video in courses increases motivation. & .815 & -.124 & .253 \\
\hline Educational video enables active learning. & .885 & .019 & -.072 \\
\hline Online chat used in educational video is very effective. & .858 & -.124 & .158 \\
\hline Courses given with educational video increase success. & -.044 & .976 & .093 \\
\hline $\begin{array}{l}\text { Courses given with educational video increase the } \\
\text { efficiency of students and courses. }\end{array}$ & -.062 & .970 & .137 \\
\hline $\begin{array}{l}\text { It is more interesting to form activities in courses given } \\
\text { with educational video. }\end{array}$ & .147 & .130 & .867 \\
\hline $\begin{array}{l}\text { Collaborative learning becomes more effective in courses } \\
\text { given with educational video. }\end{array}$ & .024 & .089 & .893 \\
\hline
\end{tabular}

Table 1. The three factors of the questionnaire 
The reliability of the factor analysis is indicated through Table 2 where the KMO and Bartlett's test have values of 0.543 and 678.169 which are satisfactory. Sig is $0.000<0.05$ so the results are statistically significant at a significance level $>5 \%$.

\begin{tabular}{|l|c|r|}
\hline \multicolumn{2}{|l|}{ Kaiser-Meyer-Olkin Measure of Sampling Adequacy } & .543 \\
\hline \multirow{3}{*}{ Bartlett's Test of Sphericity } & Approx. Chi-Square & 678.169 \\
\cline { 2 - 3 } & $\mathrm{df}$ & 28 \\
\cline { 2 - 3 } & Sig. & .000 \\
\hline
\end{tabular}

Table 2. KMO and Bartlett's test

The statistical analysis continues with the hierarchical regression determining not only the independent but also the dependent variables. In the present study there are 3 independent variables that have been determined by the factor analysis (motivation, efficiency, effective) and the dependent variable is "how satisfied you are with the use of the educational video".

\begin{tabular}{|l|c|r|r|r|r|r|}
\hline \multicolumn{2}{|c|}{ Model } & Sum of Squares & df & Mean Square & \multicolumn{1}{c|}{ F } & \multicolumn{1}{c|}{ Sig. } \\
\hline \multirow{3}{*}{1} & Regression & 11.978 & 3 & 3.993 & 7.631 & $.000^{\mathrm{b}}$ \\
\cline { 2 - 7 } & Residual & 60.689 & 116 & .523 & & \\
\cline { 2 - 8 } & Total & 72.667 & 119 & & & \\
\hline
\end{tabular}

Table 3. Anova Analysis

Table 3 shows the results of the hierarchical regression (anova analysis) where Sig $=0.000$ so the results are statistically significant at a significance level of $5 \%$.

In Table 4 there are the coefficients of the model with the factors efficiency and effective. These factors are statistically significant in contrast to the motivation. Both of the two factors (efficiency and effective) contribute to the model exactly the same.

\begin{tabular}{|c|c|c|c|c|c|c|}
\hline \multirow{2}{*}{\multicolumn{2}{|c|}{ Model }} & \multicolumn{2}{|c|}{ Unstandardized Coefficients } & \multirow{2}{*}{$\begin{array}{c}\begin{array}{c}\text { Standardized } \\
\text { Coefficients }\end{array} \\
\text { Beta }\end{array}$} & \multirow[b]{2}{*}{ t } & \multirow[b]{2}{*}{ Sig. } \\
\hline & & B & Std. Error & & & \\
\hline \multirow[t]{4}{*}{1} & (Constant) & 3.333 & .066 & & 50.483 & .000 \\
\hline & Motivation & .029 & .066 & .037 & .434 & .665 \\
\hline & Efficirncy & .226 & .066 & .290 & 3.415 & .001 \\
\hline & Effective & .220 & .066 & .282 & 3.323 & .001 \\
\hline
\end{tabular}

Table 4. Models' coefficients

It is concluded that in the design of an e-learning system statistically significant is the group monitoring of students and the activities (exercises - problems) that are offered for the trainees to be included in the educational video. The efficiency factor confirms that using the educational video, students have the opportunity to deeply understand the subject matter of the courses and hence to have better results in the tests and examinations of the course.

\section{Conclusion}

The use of Information and Communications Technology (ICT) in Education for the teaching of the subject unit "Simple Colloids" successfully puts into use the creative advent of new reflections and descriptions, accessible to the students' minds. The implementation of ICT in Education makes the approach to the teaching object more attractive as students through visual interactions can observe how they react dynamically to certain changes and other elements without spending time with complex mathematical computations. 
The theoretical material that is reported during video recorded educational videos introduces the basic concepts of "Simple Colloids" as well as their properties, contributes to a differentiation from solutions and mixtures, coupled with simple experiments, where the student will be able to observe everything he/she needs to know and especially how he/she can build and develop knowledge through his/her own experiments and observations.

It aims at creating an educational tool or a section of a wider unity that will relate to educational material and will contribute to the more integrated and correctly structured teaching of students. The realization of video recorded educational experiments was carried out with the main purpose of modifying the traditional teaching method even just a little and especially to prove, after their application, the ease of incorporation of computers in the daily routine of teaching. The majority of the teaching goals set in the video design and related to the cognitive, affective and psychomotor domain of teaching are estimated to have been largely achieved by this action and this easily has concluded from the statistical analysis which has realized it the present work.

It would be a substantial omission not to refer to the association of phenomena with examples from everyday life, as it can gain the consequently increased interest of students. Chemistry is transformed into an interesting discovery process as it provides the possibility of explaining phenomena that could not be understood before. Conclusively, all these methods facilitate the understanding of the connection between macroscopic and microscopic view, resulting in the most complete and accomplished knowledge.

\section{Declaration of Conflicting Interests}

The authors declared no potential conflicts of interest with respect to the research, authorship, and/or publication of this article.

\section{Funding}

The authors received no financial support for the research, authorship, and/or publication of this article.

\section{References}

Bezemer, J., \& Kress, G. (2008). Writing in Multimodal Texts: A Social Semiotic Account of Designs for Learning. Written Communication, 25(2), 166-195. https://doi.org/10.1177/0741088307313177

Bouchoux, A., Qu, P., Bacchin, P., \& Gésan-Guiziou, G. (2014). A general approach for predicting the filtration of soft and permeable colloids: the milk example. Langmuir, 30(1), 22-34.

https://doi.org/10.1021/la402865p

Cosgrove, T. (2005). Colloid Science Principles, Methods and Applications. Blackwell, Bristol.

Education \& Training Division (2013). Organization for Further Education and Certification Educational material for the training of teachers in the Training Support Centers. Issue 1, General Part, CTI Diophantus - Further Education and Training Division of Patra (in Greek).

Freire, P. (1977a). Pedagogy of the Oppressed (Greek, edition), Rappa, Athens (in Greek).

Kelly, G.A. (1955). The psychology of personal constructs. New York, Norton.

Koulaidis, V. (2007). Contemporary teaching approaches for the development of critical-creative thought. OEPEK, Athens (in Greek).

Kress, G. (2003). Literacy in the new media age. Routledge, London. https://doi.org/10.4324/9780203299234

Matsagouras, E. (2011). Theory and Practice of Teaching, Gutenberg - Dardanos, Athens (in Greek).

Thysiadou, A., Mitropoulos, A., Sakla, I., \& Giannakoudakis, P. (2019). Attract the Student's Interest with the Use of Videos for the Teaching of the "Acid-Bases-Salts" Module. Proceedings of the International Conference on Information Technologies (InfoTech), IEEE (1-4). Bulgaria.

https://doi.org/10.1109/InfoTech.2019.8860891 
Thysiadou, A., Solomanidou, A., \& Christoforidis, S. (2020). Inspiring students' enthusiasm with the help of educational videos for the more effective teaching of "Chemical Kinetics and Chemical Equilibrium. Journal of Engineering Science and Technology Review SI, 294-298.

Vygotsky, L.S. (2008). Thought and Language, Gnosi, Athens (in Greek).

Published by OmniaScience (www.omniascience.com)

Journal of Technology and Science Education, 2021 (www.jotse.org)

\section{(c) (1) (5)}

Article's contents are provided on an Attribution-Non Commercial 4.0 Creative commons International License. Readers are allowed to copy, distribute and communicate article's contents, provided the author's and JOTSE journal's names are included. It must not be used for commercial purposes. To see the complete licence contents, please visit https://creativecommons.org/licenses/by-nc/4.0/. 